\title{
Digital Dividend: The Path Towards Business and Marketing Development
}

\author{
George Mastorakis \\ Technological Educational Institute of Crete, Heraklion, Greece
}

\begin{abstract}
Wireless radio spectrum is an important resource that allows for increased business development, through the provision of services using wireless networking infrastructures. Since radio spectrum is limited, an optimal utilization of it is required, by adopting advanced spectrum management methods. The current transition from analogue to digital terrestrial television may act as a unique opportunity, in order to reallocate this valuable spectrum resource. After the transition, a part of the traditional analogue television spectrum bands will be completely released, allowing for the use of this spectrum by sophisticated wireless systems. Furthermore, digital terrestrial television interleaves spectrum bands in order to avoid possible interference between adjacent channels used by broadcasting stations, thus leaving spectrum holes exploited by novel wireless networks, namely unlicensed secondary systems. In this context, this article investigates business and marketing development issues, arising by utilizing released and interleaved television spectrum bands.
\end{abstract}

Keywords: radio spectrum, digital dividend, business and marketing development

\section{Introduction}

Information and communication technologies (ICT) enable a large number of users worldwide to receive advanced real time services provided by sophisticated networking platforms. More specifically, access to mobile broadband networks, in the case where wire-line access is restricted, enables users to ubiquitously communicate at anytime. From the European Union's (EU) perspective, the Lisbon Treaty envisions providing significant improvements in mobile broadband multimedia services and internet access for European citizens. For this purpose, the European Commission puts effort to create a pan-European network of mobile services through the harmonization of spectrum use by all EU member states in the future. Furthermore, television radio spectrum, which is a range of low frequencies in VHF and UHF bands, is traditionally used exclusively by analogue television broadcasters. This part of the radio spectrum offers attractive features, such as high penetration of buildings, wide coverage and moreover, the wavelength of the UHF band signals is short enough such that resonant antennas with small footprint can be used, enabling the provision of signals to many portable and handheld devices. However, regulatory rules do not allow unlicensed devices in the television bands, except

George Mastorakis, Ph.D., Assistant Professor, Department of Commerce and Marketing, Technological Educational Institute of Crete.

Correspondence concerning this article should be addressed to George Mastorakis, Department of Commerce and Marketing, Technological Educational Institute of Crete, Ierapetra, 72000, Crete, Greece. E-mail: g.mastorakis@emark.teicrete.gr. 
of the remote control devices, medical telemetry devices and wireless microphones (PMSE).

Currently, there is a global move to switchover from analogue to digital terrestrial television. This is called digital switchover (DSO), or in some cases, the analogue switch (ASO), referring to the time when digital terrestrial broadcasting begins, or when analog broadcasting ends, respectively. Although the DSO process is underway in the EU, the ASO process will be different from country to country, depending on the configuration of the market. It is predictable that the request by the European Commission for completion of the ASO in 2012 will be difficult to achieve in a number of member states. On the other hand, it is expected that the experiences of countries that have completed the ASO or undertaken extensive planning will provide useful lessons for countries just beginning the planning process. Due to the spectrum efficiency of digital terrestrial television, some of the spectrum bands used for analogue television will be totally cleared and made available for usage by other wireless networks. Additionally, DTV spectrum allocation is such that there are a number of television bands, which remain unused in given geographical locations, so as to avoid causing interference between digital terrestrial television stations. The spectrum bands are in this way geographically interleaved. The cleared bands and the unused geographically interleaved spectrum bands, provide an opportunity to offer new services by deploying sophisticated wireless networks. These opportunities create what is called "digital dividend". For the European Commission, the "digital dividend” (i.e., cleared spectrum and geographically interleaved spectrum) (DigiTAG, 2009) is a great opportunity to achieve important objectives of the EU Lisbon strategy (EC, 2010), especially regarding the provision of mobile broadband Internet services.

Market analysis shows that the "digital dividend" in Europe is a unique opportunity to realize economic/social benefits across EU countries. This is a key issue to maintain competitiveness in Europe, especially considering "digital dividend" progress in other areas. Additionally, secondary markets initiatives in Europe lag behind the rest of the developed world and a very little progress has been in developing frameworks for secondary trading between wireless networks systems at European level. The "digital dividend” could be valuably employed by cognitive radio (CR) networks. A CR network (Akyildiz, Lee, Vuran, \& Mohanty, 2006) is a key enabler for both real-time spectrum markets (ACMA, 2007) and dynamic sharing of licensed spectrum by unlicensed devices. CR networks perform spectrum acquisition, either through purchasing (in cleared spectrum) or sensing (in geographically interleaved spectrum) over a frequency range, dynamically acquire unused spectrum and then operate at time intervals and locations when and where it is possible for them to transmit in a non-interference basis, while achieving optimum quality of service (QoS). Currently CR networks are intensively investigated for proper access to TV White Spaces (TVWS), which become available in a geographical basis, after the digital switchover.

Radio Spectrum Policy Group (RSPG) published the final draft of a report on "cognitive technologies" (RSPG, 2009), which makes clear comments on the possibility of supporting trading mechanisms for CR networks. This report describes the vertical and horizontal models for the licensed sharing of spectrum. The vertical model, which is more interesting, envisages the licensed system (i.e., the digital terrestrial television broadcaster, allowing secondary use of spectrum at locations and times that it is not used). The horizontal model, on the other hand, is less relevant to horizontal sharing, as it pools the entire spectrum held by a group of licenses, such they can then access the spectrum, according to given demand profile. At the global level, the active secondary trading of spectrum is still more a concept than a reality. There are a number of landmarks that could 
mark the start of secondary trading of radio spectrum worldwide. Specifically, New Zealand started spectrum trading in 1987, Guatemala in 1996, Australia commenced in 1997 and both the Federal Communications Commission (FCC) (2004) and Ofcom (2004) adopted regulations for spectrum trading in 2004. However, there has been little activity in the economic/business and regulatory development of an active secondary trading environment for micro-trades of the kind, which might be considered in TVWS. The development of secondary trading systems in Europe has been slowed compared to other developed countries. In this case, research activities envision bridging this gap by investigating mechanisms for secondary spectrum trading and proposing relevant means to allow a secondary treatment for the spectrum in European context.

For the successful development of dynamic spectrum trading mechanisms and market models for wireless network services in TVWS, the intersection of influences from regulatory, technology and market potential aspects, is needed to be analyzed. For this purpose, this paper aims to analyze the roadmap towards the transition from analogue to digital terrestrial television in Europe and investigates the trends in the TVWS market in order to identify business and marketing development issues in the field of Information and communications technologies (ICT).

\section{Digital Switchover in Television}

Many countries worldwide have already started to allow the transmission of digital terrestrial television services and start planning to turn off their analogue networks. The process of ending the transmission of analogue television services is not an easy one. Ending analogue broadcasting services may have terrible consequences, if viewers are not adequately prepared and governments wish to ensure that the appropriate safeguards are taken. For this reason, careful network planning and the involvement of the entire broadcast industry are required. The process of analogue television switch-off differs in countries, depending on the configuration of the market. Countries with many households depending on the terrestrial television platform need to take different measures than countries with few terrestrially dependent households. The experiences of countries that have completed analogue switch-off or undertaken extensive planning can provide useful lessons for countries just beginning the planning process. Understanding which approaches have the best results, as well as pitfalls that have to be avoided, can ensure a successful process. The transition to digital terrestrial television today is largely a preoccupation of the advanced economies in the world and the major markets are the USA, Japan and Europe (in Western Europe, the United Kingdom, Spain, Germany, Italy and France).

The transition from analogue to digital terrestrial television in Europe will free valuable radio spectrum due to the increased efficiency of digital broadcasting transmission. The "digital dividend" spectrum will become available across Europe in a relatively short time, as all member states should complete the analogue switch-off by 2012. It is important that this opportunity is used to ensure proper coordination in the European Union to reap the full social and economic benefits possible from access to this spectrum and provide a clear roadmap for the EU member states for, progressing at different speeds as a result of differing national circumstances. The opening of "digital dividend" for different services creates an opportunity particularly for wireless broadband network operators to acquire a significant part of the spectrum. This will allow more 
effective competition in broadband services. Since late 2009, ten countries completed the process of turning off analogue terrestrial broadcasting. Many other countries have plans to do so or are in the process of gradual conversion. The first country to make a wholesale switch to digital terrestrial broadcasting was Luxembourg in 2006, followed by the Netherlands later in 2006, Finland, Andorra, Sweden and Switzerland in 2007, Belgium and Germany in 2008, and Denmark and Norway in 2009. Member states that started early digital terrestrial television mainly broadcast using MPEG-2 compression technology while member states that have recently begun, or are yet to start (such as Ireland, Latvia, Lithuania, Romania and Slovenia) plan to use MPEG-4 compression technology from the beginning. Austria, Denmark, Finland, Germany, Italy, Luxembourg, Portugal, Sweden and the UK all consider future migration to MPEG-4 standard to be highly unlikely. In particular, Sweden and Denmark plan to simulcast using both MPEG-2 and MPEG-4 standards in the near future.

The average period for simulcasting analogue and digital terrestrial television in member states is approximately 5.5 years. Smaller member states with large cable infrastructure, such as the Netherlands and Luxembourg, switched-off their analogue television signals on a national level overnight. Germany, as a larger nation with a large cable infrastructure, adopted a regional plan regarding this transition and had a simulcast period of about six years. However, in the United Kingdom, where terrestrial television is one of the main TV platforms, simulcasting is expected to occur for a total of 14 years before the ASO. Member states have different approaches regarding the DSO plans. The rate at which they proceed seems to depend on the geography, the landscape of television platform, the policy objectives and the political will, as well as the level of technological progress. In general, Western European member states have begun and are likely to complete DSO before the Eastern European member states. Indeed, five countries (Finland, Germany, Luxembourg, the Netherlands and Sweden) have already turned off their analogue transmissions. The European Commission's call for the completion of analogue switch-off by 2012 may be difficult to achieve for some states. Based on currently available evidence, it can be generally assumed that the digital transition will take 14 years (as in the United Kingdom) and 3 years (as in the Netherlands) from the time of the first start of digital terrestrial television to the switch-off of the last analogue services. The factors that will influence the process include the number of viewers relying on terrestrial television platform, availability of spectrum and the penetration of digital television services.

Countries that have already started digital terrestrial television services and begun to remove analogue terrestrial platform will likely complete digital switchover by 2012. However, countries that have not yet begun digital terrestrial television platforms, they risk being unable to complete the analogue broadcasting by 2012 . At this stage, all member states except Poland, seem to have confirmed their intention to complete the analogue broadcasting by 2012. Already, the process was completed by 5 member states (Finland, Germany, Luxembourg, Netherlands, Sweden), while another 8 member states (Austria, Belgium, Czech Republic, Estonia, France, Italy, Spain, United Kingdom) have begun switching off analogue services in one or more areas. It is expected that these countries will be able to complete analogue broadcasting by 2012, if not sooner. Member states which have not yet begun DTT services will have greater difficulties in achieving a sufficiently high level of penetration to allow for analogue broadcasting by 2012 . 


\section{Economic Potential of Digital Dividend}

Due to the spectrum efficiency of digital terrestrial television, some of the spectrum bands used for analogue television will be cleared and made available for other use. In addition, digital terrestrial television allocation of spectrum is such that there are a number of television bands, which remain unused in given geographical locations (geographically interleaved spectrum bands), so as to avoid causing interference. The cleared bands and unused geographically interleaved spectrum bands provide an opportunity to develop new wireless network services (Analysys Mason, 2009; RSPG, 2009; CEPT, 2008; Commision of EC, 2009; Ofcom, 2008). The economic potential and the resulting social dimension in Europe, stemming from a wise management of the "digital dividend" (cleared spectrum and TVWS), has been the subject of many studies over the past 3 years. The main findings of most studies correlate and identify the following possible uses of the "digital dividend":

- Digital terrestrial television;

- Mobile TV;

- Commercial wireless broadband services (fixed and mobile);

- Wireless broadband services for public protection;

- Services ancillary to broadcasting and program making (SAB/SAP);

- Cognitive radio technologies.

Due to the differences and particularities of each member state, the growth and demand for each of these potential "digital dividend" uses can vary considerably. However, studying a representative sample of the broader categorization of all member states, it seems that the UHF band used for terrestrial broadcasting is expected to generate $€ 750$ bn to $€ 850$ bn in net present value (NPV) for the European economy. Furthermore, the optimum coverage and features of this area are undoubtedly of great interest to key stakeholders and will require a common approach and harmonization of actions, especially by neighboring countries. In this respect, the conservative trend in Europe is to allocate a portion of the spectrum UHF (ranging from 72 to $92 \mathrm{MHz}$, in the first stage) to mobile telephony, which is estimated to generate between $€ 63$ bn to $€ 232$ bn NPV evaluating benefits for a period of 20 years. A further extension is likely to be reviewed in a second stage, after the reassessment of the market as a whole, taking into account the data updated on demand, market development and technological innovations.

In a broader perspective, the market can be analyzed under different scenarios (e.g., pessimistic, conservative and optimistic), in which the main key drivers are the digital terrestrial television and Wireless Broadband Service growth/demand and the relationship between them. These parameters are then interpreted into financials figures, considering either a specific allocation of UHF spectrum for each service (e.g., 790 MHz-862 MHz sub-band for mobile telephony) or in different regions of spectrum allocation for each service in order to identify the optimal allocation of the band with various possible uses of the "digital dividend". In order to quantify the prediction of growth and demand for wireless broadband services, and finally to interpret direct and indirect economic benefits, the models are using measurable key activities, such as video (streaming and downloading measured in minutes per month), navigation (pages/month), music (tracks/month), e-mail (e-mails/month), mobile TV (min/month) and other business applications, all referring to a representative "file size per use".

The direct benefits are those resulting from direct consumption of mobile broadband services and are divided into the cost/benefits due to the producers and those due to consumers. For producers of mobile 
broadband services, directly benefits mainly result from the reduction of network costs. If these cost savings were retained by operators or their shareholders, this would add to the producer surplus. However, since this market is very competitive, it can safely assume that almost $100 \%$ of the cost savings are ultimately passed on in price changes. Reduced prices for mobile broadband services will facilitate the increased use of consumer services and the incremental benefit to consumers or consumer surplus is the additional use in conjunction with lower prices for the current year. Indirect benefits result from the indirect effects of the market for those services have on other product markets and, consequently, may further increase total surplus of consumers and producers. For example, some of the additional revenues from mobile broadband service could be derived from marketing or incensement of electronic commerce and not only by the subscribers. However, especially for the marketing revenues, they do not represent an economic benefit but a financial flow or an expense by the advertiser as part of his marketing strategy, which leads to higher sales and profits for producers in other parallel markets.

Externalities are the wider economic benefits for society as a whole, and not taken into account by the consumer or producer when selling the product or service. These will include increased productivity of workers, since business applications will be available easier and more efficient ways to produce additional jobs, strengthen the related industries, etc.. Furthermore, as a further social adds on, the improvement of quality of service can be considered as well as the enhancement of the safety and security related applications that promote a better quality of life for citizens.

\section{Conclusion}

Currently, there is a global move to switch television stations operating from analogue to digital terrestrial transmission. Due to the spectrum efficiency of digital terrestrial television, some radio spectrum bands used for analogue television will be cleared and made available for other uses. This paper analyses the transition from analogue to digital terrestrial television in Europe, which will free valuable radio spectrum due to the increased efficiency of digital broadcasting. The "digital dividend" has great potential for providing a wide range of services, as the radio signals in this range travel far and the equipment can be easily used indoors. It is a unique opportunity for Europe to meet the growing demands for spectrum, particularly to provide wireless broadband in rural areas, thus bridging the digital divide and to facilitate the emergence of new wireless network services such as next generation mobile broadband, as well as to support the development of digital terrestrial broadcasting. Therefore, it can contribute significantly to achieving the Lisbon goals on competitiveness, economic growth, as well as on business and marketing development, satisfying some of the important social, cultural and economic needs of EU citizens.

\section{References}

Akyildiz, I. F., Lee, W. Y., Vuran, M. C., \& Mohanty, S. (2006). Next generation/dynamic spectrum access/cognitive radio wireless networks: A survey. Computer Networks, 50(13), 2127-2159.

Analysys, M., DotEcon, Hogan, \& Hartson. (2009). Exploiting the digital dividend-An European approach. Report to the European Commission.

Australian Communication and Media Authority (ACMA). (2007). The economics of spectrum management: A review. Retrieved from http://www.acma.gov.au/webwr/aca_home/publications/reports/spectrum\%20-\%20final\%20draft\%20-\%203.pdf

CEPT REPORT 25. (2008). Technical roadmap proposing relevant technical options and scenarios to optimize the digital dividend, including steps required during the transition period before analogue switch-off. Retrieved from http://www.erodocdb.dk/docs/doc98/official/pdf/CEPTRep025.pdf

Commission of the European Communities. (2009). Transforming the digital dividend into social benefits and economic growth, Communication from the Commission to the European Parliament, the Council, the European Economic and Social Committee 
and the committee of regions. Retrieved from http://www.eesc.europa.eu/?i=portal.en.ten-opinions.19524

DigiTAG. (2009). The digital dividend and the future of digital terrestrial television. Retrieved from http://www.digitag.org/DTTResources/DigiTAG_Position_Paper\%201.01.pdf

European Commission. (2010). Lisbon strategy evaluation document. Brussels. Retrieved from http://ec.europa.eu/europe2020/pdf/lisbon_strategy_evaluation_en.pdf

FCC. (2004). Second Report and Order, Order on Reconsideration, and Second Further Notice of Proposed Rulemaking (FCC 04-167): Promoting Efficient Use of Spectrum Through Elimination of Barriers to the Development to Secondary Market.

Ofcom. (2004). A statement on spectrum trading: Implementation in 2004 and beyond. Retrieved from http://hraunfoss.fcc.gov/edocs_public/attachmatch/FCC-04-167A1.pdf

Ofcom. (2008). Digital dividend review: geographic interleaved awards 470-550 MHz and 630-790 MHz-Consultation on detailed award design. Retrieved from http://stakeholders.ofcom.org.uk/binaries/consultations/spec_trad/statement/sts.pdf

RSPG. (2009). Radio spectrum policy group report on "cognitive technologies". Final Draft. Retrieved from http://www.itst.dk/frekvenser-og-udstyr/internationalt-samarbejde/eu-samarbejdet-pa-radiofrekvensomradet/rspg-radio-spect rum-policy-group/rspg-filmappe/20/RSPG09-299\%20Draft\%20RSPG\%20Report\%20on\%20Cognitive\%20Technologies\%2 0final\%20draft.pdf

RSPG Secretariat. (2009). Radio spectrum policy group report on cognitive technologies. Radio Spectrum Policy Group, Electronic Communications Policy. Brussels: European Commission—Information Society and Media Directorate-General. 